\title{
Facially amphiphilic thiol capped gold and silver nanoparticles ${ }^{\dagger}$
}

\author{
SHREEDHAR BHAT ${ }^{\mathrm{a}}$ and UDAY MAITRA* \\ Department of Organic Chemistry, Indian Institute of Science, Bangalore 560012 \\ ${ }^{a}$ Current address: ISM, University of Bordeaux, France \\ e-mail: maitra@orgchem.iisc.ernet.in
}

\begin{abstract}
A series of bile acid-derived facially amphiphilic thiols have been used to cap sliver and gold nanoparticles. The self-assembling properties of these steroid-capped nanoparticles have been investigated and reported in this article.
\end{abstract}

Keywords. Bile acid; facially amphiphilic thiol; metal nanoparticles; self-assembly; organic-inorganic hybrid materials.

\section{Introduction}

There is a growing need to prepare and understand the properties of nano-sized objects due to rapid growth of nanotechnological applications. Noble metal nanoparticles are of interest as colourants, ${ }^{1}$ metal coatings, ${ }^{2}$ electronics, ${ }^{3}$ optics, ${ }^{4}$ chemical catalysis, ${ }^{5}$ and medicine. ${ }^{6}$ Gold nanoparticle has also been known as an aesthetic red colourant for stained glass and fine glassware, such as Venetian glass. ${ }^{7}$

Generally, gold nanoparticles are easily produced in a liquid ('liquid chemical methods') by the reduction of chloroauric acid $\left(\mathrm{HAuCl}_{4}\right)$, although more advanced and precise methods exist. As the neutral gold atoms form, the solution becomes supersaturated, and gold gradually starts to precipitate in the form of nanoparticles.

To prevent the particles from further aggregation, stabilizing agents that bind to the nanoparticle surface are essential. Such agents can be organic ligands to create organic-inorganic hybrids with advanced functionality, ${ }^{8}$ allowing one to tune their material properties. Such hybrid materials may have significant applications in a wide variety of areas, including electronics, and (nano)biotechnology.

In this article, we summarize the synthesis and characterization of facially amphiphilic bile thiol stabilized gold and silver nanoparticles and their aggregates.

\footnotetext{
${ }^{\dagger}$ Dedicated to Prof. C N R Rao on his 75th birthday

*For correspondence. Also at the Chemical Biology Unit, Jawaharlal Nehru Centre for Advanced Scientific Research,
} Bangalore 560064

\section{Materials and methods}

Gold trichloride $\left(\mathrm{AuCl}_{3}\right)$, and sodium borohydride $\left(\mathrm{NaBH}_{4}\right)$ were purchased from Aldrich and used as received. All the glassware used in the experiments were acid rinsed prior to wash and dried in a hot oven. Organic solvents were distilled prior to use. Water was double distilled over $\mathrm{KMnO}_{4}$ to remove organic impurities. Glacial acetic acid was obtained from Ranbaxy Chemicals. Absorption spectra were recorded on a SHIMADZU UV-2100 spectrophotometer.

\subsection{Synthesis of the capping agents (stabilizing agents)}

The stabilizing agents, 1-3 or 4-6 (chart 1), containing a thiol/sulfide moiety at the bile acid side-chain were synthesized using functional group transformation starting from commercially available bile acids and the experimental details on the synthesis of thiols have been published elsewhere. ${ }^{10}$
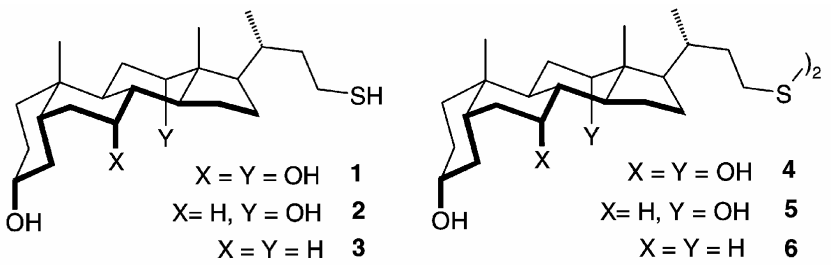

Chart 1. Chemical structure of the thiols or disulfides used for the nanoparticle preparation. 


\subsection{Synthesis of the nanoparticles}

2.2a General procedure for the preparation of steroid capped gold nanoparticles: A solution containing 1 equiv. of $\mathrm{HAuCl}_{4}$ in methanol and 0.5 equiv. of steroid disulfide $[4,5$ or 6$]$ (or 1 equiv. of thiol $[1,2$ or 3$]$ with $\mathrm{S} / \mathrm{Au}=1$ ) was stirred for $1 \mathrm{~h}$ for thorough mixing and the mixture was homogeneous. Sodium borohydride (10-15 times excess) in $\mathrm{MeOH}$ was added drop-wise to the stirring mixture. The deep yellow colour of the gold chloridesteroid thiol mixture turned to dark brown immediately upon addition of borohydride. Stirring was continued for an additional $2 \mathrm{~h}$. After cooling the mixture $\left(<-15^{\circ} \mathrm{C}\right)$ in a freezer the particles settled at the bottom of the flask. The supernatant was removed by decantation.

(i) $(3)_{\mathrm{m}}(\mathrm{Au})_{\mathrm{n}}$ : Plasmon absorption $\left(\lambda_{\max }\right) 515 \mathrm{~nm}$; Average particle size $=1.5 \mathrm{~nm}$; Anal.: $\mathrm{C} 11.25 \%, \mathrm{H}$ $1.7 \% ; \mathrm{m} / \mathrm{n}$ calculated $=0.094$. The $m / n$ ratio gives an idea of number of bile acid units per Au.

(ii) $(2)_{\mathrm{m}}(\mathrm{Au})_{\mathrm{n}}$ : Plasmon absorption $\left(\lambda_{\max }\right) 520 \mathrm{~nm}$; Average particle size $=2.5 \mathrm{~nm}$; Anal. C $12.92 \%, \mathrm{H}$ $1.87 \% ; \mathrm{m} / \mathrm{n}$ calculated $=0.112$.

(iii) $(1)_{\mathrm{m}}(\mathrm{Au})_{\mathrm{n}}$ : Plasmon absorption $\left(\lambda_{\max }\right)$ $518 \mathrm{~nm}$; Average particle size $=3.5 \mathrm{~nm}$; Anal. C $14 \cdot 76 \%, \mathrm{H} 2 \cdot 16 \%, \mathrm{~m} / \mathrm{n}$ calculated $=0 \cdot 134$.

$2.2 \mathrm{~b}$ General procedure for the preparation of steroid capped silver nanoparticles: A reported procedure was followed to synthesize bile thiol capped silver nanoparticles. ${ }^{11}$ An ethanolic solution of $\mathrm{AgNO}_{3}\left(3 \times 10^{-2} \mathrm{M} ; 10 \mathrm{~mL}\right)$ was mixed with a bile thiol $\left(1.3 \times 10^{-4} \mathrm{M}\right)$ and the mixture was stirred for $1 \mathrm{~h}$. A saturated solution of $\mathrm{NaBH}_{4}$ in EtOH was added drop-wise to this vigorously stirred mixture. Stirring was continued for an additional $2 \mathrm{~h}$. After complete reduction, the mixture was cooled to $-18^{\circ} \mathrm{C}$ and the colloidal silver was collected by decantation of the supernatant. The formation of nanoparticles was confirmed from the absorption spectra of the isolated material dispersed in $\mathrm{EtOH}$.

2.2c General method of purification/isolation for the nanoparticles: The metal nanoparticles obtained were purified by re-precipitation. To a solution containing the nanoparticles in $90 \% \mathrm{EtOH} / \mathrm{CHCl}_{3}$, hexane was added slowly and the mixture was cooled in the deep freezer till the metal particles separated out. This procedure was repeated at least three times to get pure nanoparticles. The mixture was filtered and the residue was re-dissolved in $1: 1 \mathrm{EtOH} /$ chloroform. Finally, the solution was dried under vacuum.

\subsection{A chemical reaction on the capped Au nanoparticles}

Gold nanoparticles capped with thiol 3 (5 mg) were taken in a $5 \mathrm{~mL}$ rb flask fitted with a septum under a nitrogen atmosphere, dissolved in $0.4 \mathrm{~mL}$ of dry pyridine and cooled in an ice bath. $\mathrm{AcCl}(0.1 \mathrm{~mL})$ was added to this solution. The reaction mixture was allowed to warm to the room temperature, stirred for $12 \mathrm{~h}$ and quenched by the addition of $5 \mathrm{~mL}$ of dil. $\mathrm{HCl}$. The precipitated solid was collected by decantation, and the residue was dissolved in $\mathrm{CHCl}_{3}$ and washed with dil. $\mathrm{HCl}(5 \mathrm{~mL} \times 2)$, finally with distilled water $(5 \mathrm{~mL} \times 3)$. The organic layer was mixed with $15 \mathrm{~mL}$ of $\mathrm{MeOH}$ and stirred to precipitate the pure acetylated steroid-Au nanoparticles.

\subsection{Aggregation of 1-capped nanoparticles}

A solution of gold nanoparticles of 1 in $0.2 \mathrm{~mL}$ $\mathrm{AcOH}$ was diluted to $1 \mathrm{~mL}$ carefully with double distilled water. The sample was allowed to stay at room temperature $\left(27^{\circ} \mathrm{C}\right)$ for $1 \mathrm{~h}$.

\subsection{TEM imaging of the samples}

A drop of the dilute suspension was placed on a copper grid. The grid was allowed to dry under ambient condition for $24 \mathrm{~h}$ and then vacuum dried. The samples were imaged on a Tecnai $F 30$ transmission electron microscope.

\section{Results and discussion}

\subsection{Capped gold nanoparticles}

Our initial attempt to prepare gold nanoparticles in a biphasic system ${ }^{12}$ using tetraoctylammonium bromide resulted in a black residue which did not show the gold plasmon band. On the other hand, the $\mathrm{Au}$ nanoparticles prepared by the $\mathrm{NaBH}_{4}$ reduction of the yellow homogeneous solution of $\mathrm{HAuCl}_{4}$ in the presence of steroidal thiols or disulfides in methanol, keeping a $1: 1$ molar ratio between the gold salt and the steroidal thiol, showed characteristic surface plasmon band of the gold. Under vigorous stirring condition $(1000 \mathrm{rpm})$ the nanoparticles obtained were 
nearly monodisperse. This method avoids contamination of the nanoparticles from the phase transfer agents. The steroid-capped AuNPs so prepared were stable through several cycles of drying and re-dissolution. Ethanolic dispersions of the capped nanoparticles could be stored for several years without decomposition.

3.1a Absorption spectra of capped Au nanoparticles: Steroid capped gold NPs showed a surface plasmon resonance band at $520 \mathrm{~nm}$, characteristic of gold colloid. ${ }^{10}$ The shapes of the observed plasmon resonance bands were dependent on the type of the steroidal capping agent (mono, di or tri hydroxycholane-thiol). ${ }^{10}$

3.1b Electron Microscopic studies: The size and shape of the steroid-capped NPs were studied by transmission electron microscopy (TEM). The average sizes of 1-, 2- and 3-stabilized gold NP were found to be $3.5,2.5$, and $1.5 \mathrm{~nm}$, respectively, which possibly explain the observed shapes of the plasmon absorption bands. We have found that a nanoparticle of $2 \mathrm{~nm}$ contains about 20-25 steroidal units depending on the type of the steroidal cap used..$^{10,13,14 a}$

The capped nanoparticles were found to be insoluble in most of the common polar and non-polar organic solvents including water, $\mathrm{MeOH}$, EtOH, EtOAc, $\mathrm{CHCl}_{3}$, dimethylsulfoxide, etc. But they were soluble in mixed solvents of alcohols and their dispersibility profile is given in table 1. A photograph of the dispersions is shown in figure 1.

3.1c A chemical reaction on the capped gold nanoparticles: We chose acetylation as one of the simplest reactions to carry out on the capped gold nanoparticles. Gold nanoparticles stabilized by $\mathbf{3}$ comprise of a single hydroxyl group at the 3 position of the steroidal backbone, which was acetylated in pyridine-acetyl chloride to demonstrate a functional group transformation on the capped nanoparticles. ${ }^{15}$ The acetylated nanoparticles retained the characteristic plasmon resonance band of gold at $520 \mathrm{~nm}$ after the reaction. The acetyl signal appeared at $2.32 \mathrm{ppm}$ in the ${ }^{1} \mathrm{H}-\mathrm{NMR}$ and an IR band at $1739 \mathrm{~cm}^{-1}$ (characteristic ester $\mathrm{C}=\mathrm{O}$ stretching).

3.1d Aggregation study of the capped metal particles: ${ }^{14 b, 16}$ Since the synthesized Au-NPs are capped with facially-amphiphilic species, they are expected to form aggregates in aqueous medium. We focused our interest on the formation of self- assembled capped-nanoparticle clusters. The aggregation study of the nanoparticles was carried out with a representative sample of the metal nanoparticle series (1-capped gold nanoparticles, 1AuNP) as follows.

These nanoparticles (1-AuNP) were not dispersible in water alone, while they could be easily dispersed in $\mathrm{AcOH}$. Therefore, an aqueous dispersion of these nanoparticles was made using $\mathrm{AcOH}$ as the cosolvent. ${ }^{17}$ The aggregates formed in $20 \% \mathrm{AcOH} /$ water dispersion were analysed by different techniques.

The size and shape of the aggregates were characterized by electron microscopy. TEM images of 1AuNP dispersed in $20 \% \mathrm{AcOH} /$ water $(0.05 \mathrm{mg} / \mathrm{mL}$, figure 2) showed spherical clusters with diameter $\sim 30 \mathrm{~nm}$.

There was no appreciable shift of the plasmon absorption band when the capped nanoparticles were dispersed in an aqueous medium $\left(\mathrm{AcOH} / \mathrm{H}_{2} \mathrm{O}\right)$. The absorption spectra of the 1-AuNP in $20 \% \mathrm{AcOH} /$ water did not show significant change in the plasmon band and hence we conclude that the aggregation process largely involves the amphiphilic portion of the capped NPs.

The aggregation of the capped nanoparticles is probably driven by both hydrophobic effect and the hydrogen bonding on the capping agent used for the nanoparticle preparation. Pyrene solubilization experiments performed to assess the aggregation process of the capped nanoparticles could not be carried out because of the quenching of pyrene fluorescence by gold.

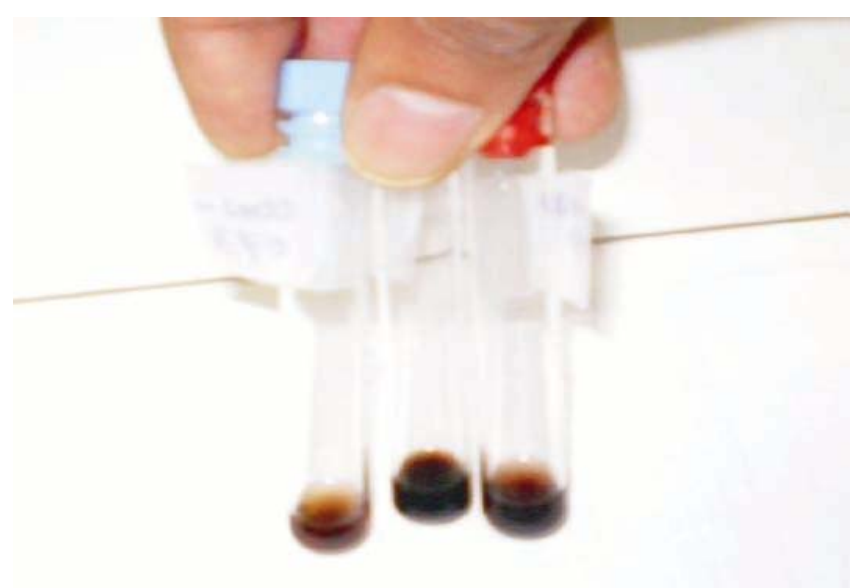

Figure 1. A photograph of the steroid capped gold nanoparticle dispersions (1, 2 and 3 capped NPs from right to left). 
Table 1. The dispersibility profile of gold nanoparticles in various solvent mixtures (tested at $1 \mathrm{mg} / \mathrm{mL}$ ).

\begin{tabular}{|c|c|c|c|}
\hline Solvents & 1-AuNP & 2-AuNP & 3-AuNP \\
\hline Hexane & ID & ID & ID \\
\hline Toluene & ID & ID & ID \\
\hline $\mathrm{CHCl}_{3}$ & ID & ID & SD \\
\hline EtOAc & ID & ID & ID \\
\hline $1: 1 \mathrm{EtOAc} / \mathrm{CHCl}_{3}$ & ID & ID & SD \\
\hline $1: 1 \mathrm{EtOH} / \mathrm{EtOAc}$ & $\mathrm{D}$ & $\mathrm{D}$ & SD \\
\hline $10 \% \mathrm{EtOH} / \mathrm{CHCl}_{3}$ & $\mathrm{D}$ & $\mathrm{D}$ & $\mathrm{D}$ \\
\hline EtOH & SD & $\mathrm{D}$ & $\mathrm{D}$ \\
\hline $90 \% \mathrm{MeOH} / \mathrm{CHCl}_{3}$ & $\mathrm{D}$ & D & $\mathrm{D}$ \\
\hline $\mathrm{MeOH}$ & SD & $\mathrm{D}$ & $\mathrm{D}$ \\
\hline DMSO or DMF & $\mathrm{D}$ & $\mathrm{D}$ & $\mathrm{D}$ \\
\hline Isopropanol & $\mathrm{D}$ & $\mathrm{D}$ & $\mathrm{D}$ \\
\hline$n$-Butanol or $t-\mathrm{BuOH}$ & $\mathrm{D}$ & $\mathrm{D}$ & $\mathrm{D}$ \\
\hline $10 \%$ Water/EtOH or $\mathrm{MeOH}$ & SD & SD & SD \\
\hline $1: 1$ Water/EtOH & SD & SD & SD \\
\hline Water & ID & ID & ID \\
\hline $\mathrm{AcOH}$ & $\mathrm{D}$ & $\mathrm{D}$ & SD \\
\hline
\end{tabular}

ID, Indispersible; SD, Sparingly dispersible; D, Dispersible

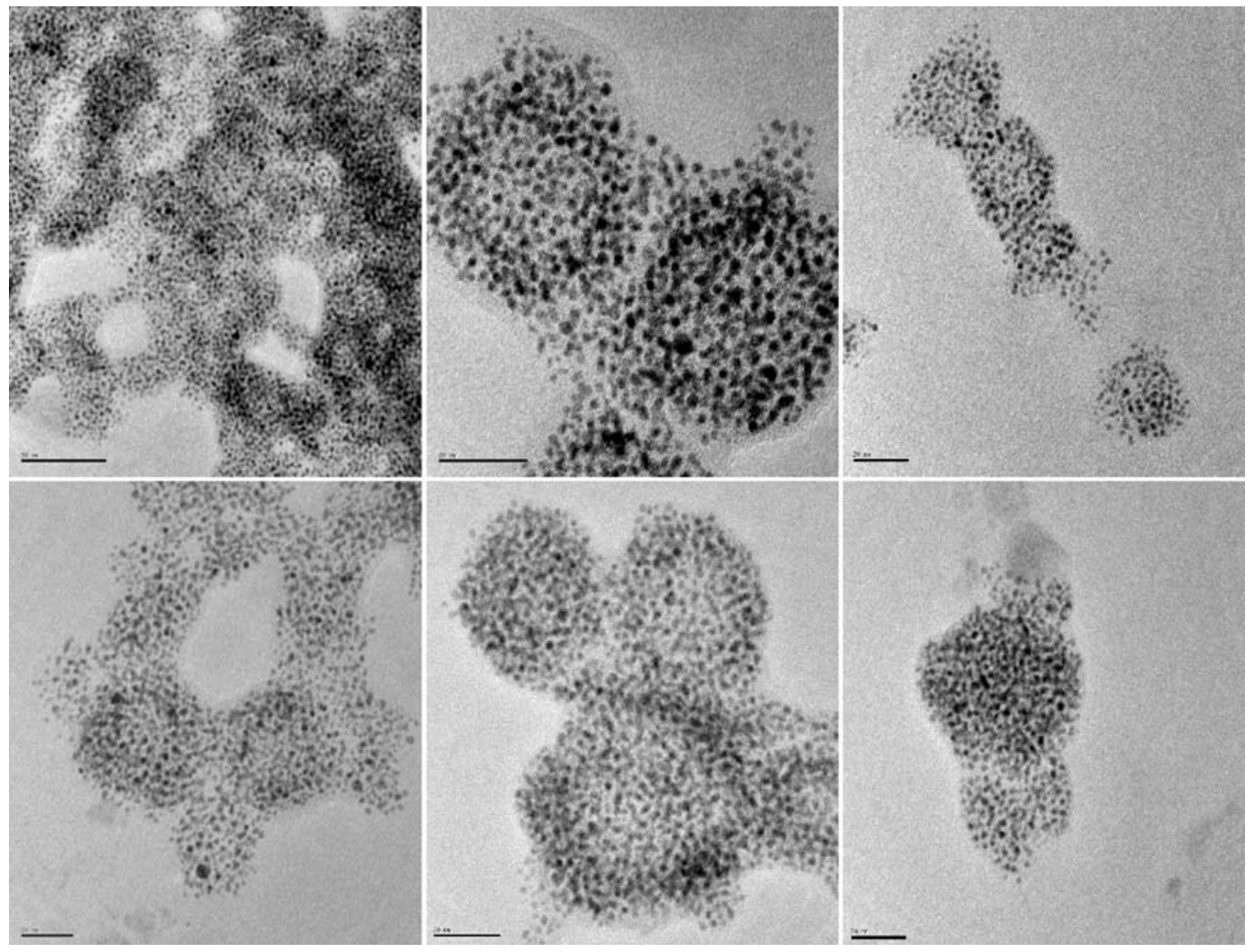

Figure 2. TEM images of 1-AuNP dispersed in $20 \% \mathrm{AcOH} / \mathrm{H}_{2} \mathrm{O}(0.05 \mathrm{mg} / \mathrm{mL})$, spherical clusters are seen. Scale bars: top left $-50 \mathrm{~nm}$, all other images $20 \mathrm{~nm}$.

\subsection{The capped silver nanoparticles}

To study the general applicability of the stabilization protocol of metal nanoparticles by bile acid derived thiols, we attempted the preparation of bile thiol stabilized Ag nanoparticles. The steroid capped $\mathrm{Ag}$ nanoparticles were not as stable as gold nanoparticles. At low temperature $\left(0-4^{\circ} \mathrm{C}\right)$, they can be stored for several months. We noticed that prolonged storage (more than 10 months) of the capped $\mathrm{Ag}$ 

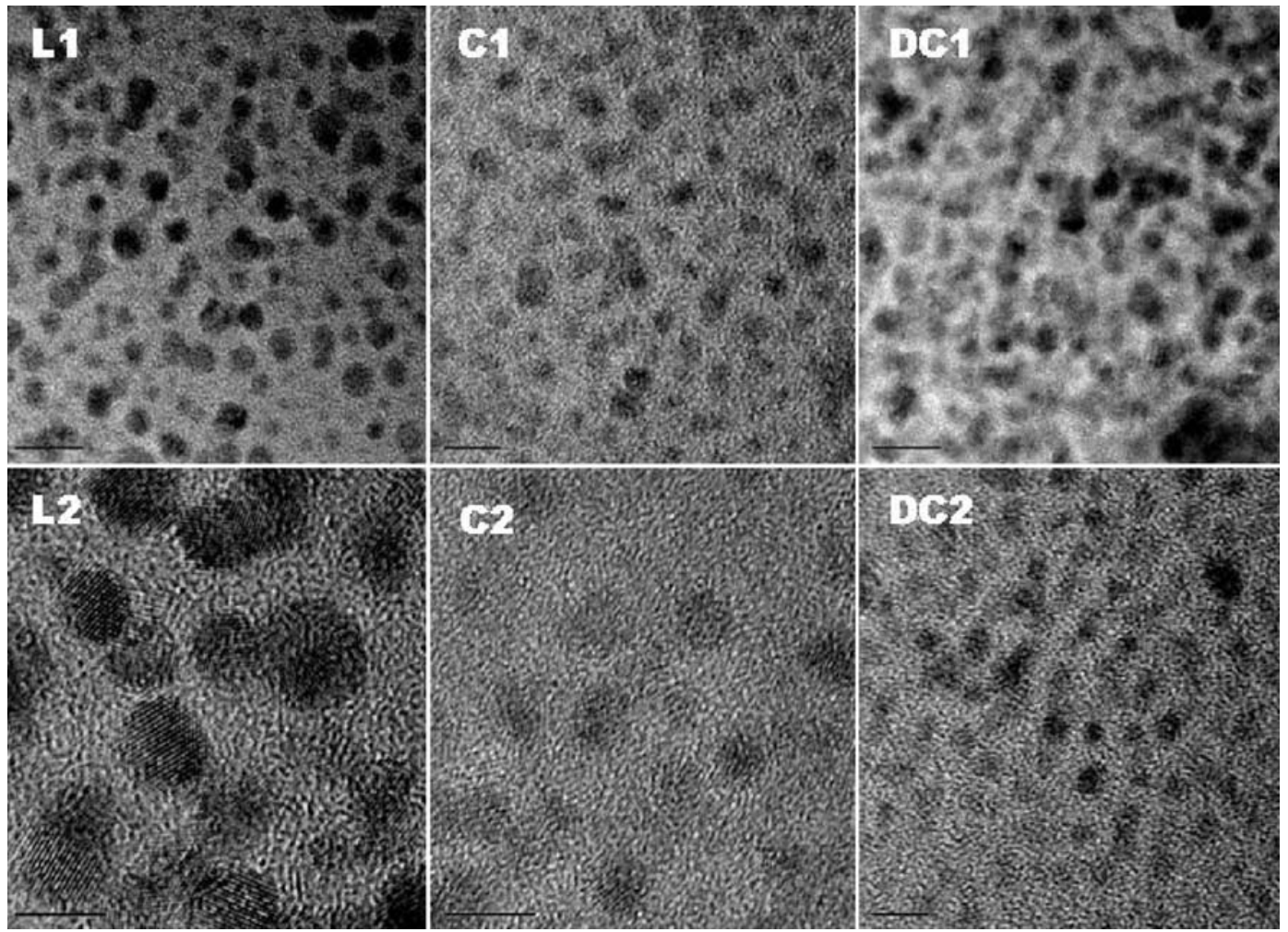

Figure 3. TEM images of silver nanoparticles stabilized by thiols derived from bile acid. L1, L2 - 3-AgNP, C1, C2 - 1-AgNP, DC1, DC2 - 2-AgNP. Scale bars: L1 - $100 \mathrm{~nm}, \mathrm{~L} 2-5 \mathrm{~nm}$, $\mathrm{C} 1-10 \mathrm{~nm}, \mathrm{C} 2-5 \mathrm{~nm}, \mathrm{DC} 1-10 \mathrm{~nm}, \mathrm{DC} 2-5 \mathrm{~nm}$.

nanoparticle dispersion slowly leads to precipitation of the black particles that cannot be redispersed after isolation. This is probably indicative of the collapse of capped nanoparticle into bulk Ag particles.

TEM images of the capped silver nanoparticles (figure 3) revealed that the average size of 1 and 3 stabilized AgNP was close to $3 \mathrm{~nm}$. The 2-capped nanoparticles were found to be smaller $(2 \mathrm{~nm})$ in comparison to the other two. The observed difference correlates with the absorption spectra (figure 4).

3.2a Absorption spectra of Ag nanoparticle dispersions: The steroid capped Ag nanoparticles showed plasmon absorption band at about $430 \mathrm{~nm}$ $\left(\lambda_{\max }\right)$, characteristic of a silver colloid (figure 4). The shape of the resonance band looks quite similar in all these cases. However, the broadness of the absorption band changed with the nature of the steroidal backbone used for capping. We speculate that this difference is because of their packing arrangement on the metal particle and deoxycholic thiol 2 forms unique arrangement on the metal particle. It is clear from figure 4 that the 2-AgNP showed the narrowest absorption band, similar to dodecanethiol stabilized Ag nanoparticles.

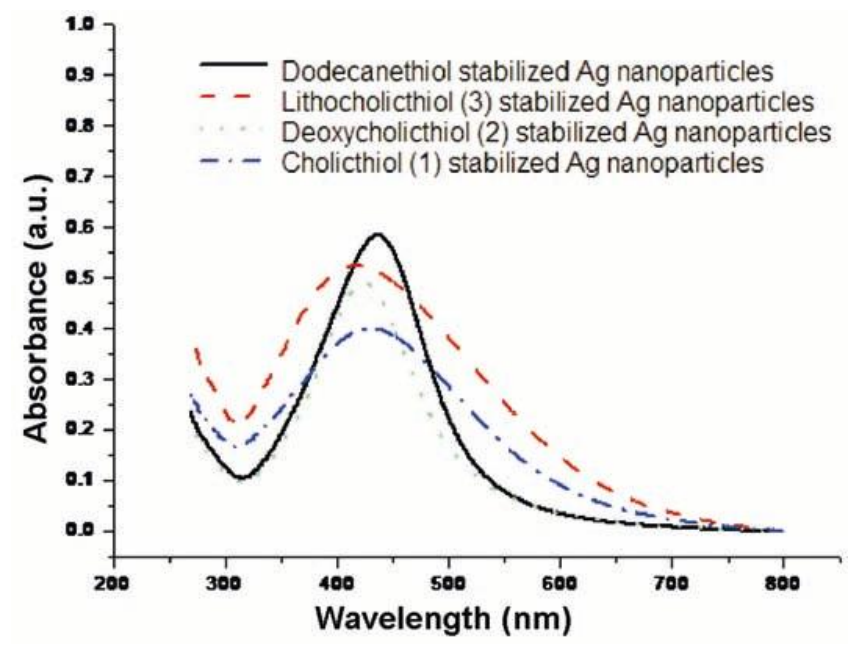

Figure 4. Surface plasmon absorption bands observed for 1-3 and dodecanethiol stabilized silver nanoparticles.

$3.2 \mathrm{~b}$ The nanoparticle dispersion: Silver nanoparticles stabilized by steroidal thiols were stable to several cycles of drying and re-dissolution. $\mathrm{Ag}$ nanoparticles capped with 1-3 could be redispersed in a variety of organic solvents. Though the range of dispersibility is similar to gold nanoparticles (table 1), these nanoparticles are sparingly dispersible in 
$\mathrm{CHCl}_{3}$ and dispersible in EtOH. The amount of alcohol required to disperse silver nanoparticles in non-polar solvents was as low as $10 \mu \mathrm{L}$ per $1 \mathrm{~mL}$, indicating their ease of dispersibility as compared to their gold counterparts.

\section{Conclusions}

In conclusion, steroid capped noble metal nanoparticles were synthesized and characterized using various techniques such as TEM, elemental analysis, FTIR and ${ }^{1}$ H-NMR. It was demonstrated that bile acid derived thiols can cap and stabilize the metal nanoparticles as efficiently as long alkyl chain thiols. These capped nanoparticles could be easily dispersed in many nonpolar solvents in the presence of an alcohol and their dispersions are stable for more than a year. The size distribution of the nanoparticles was evaluated using microscopic techniques. A comparison between capped Ag and Au nanoparticles has been made. These nanoparticles exhibited a tendency to agglomerate in aqueous medium due to the amphiphilic nature of the stabilizers 1-3. TEM analysis of the aqueous dispersion of the nanoparticles indicated the presence of closely-packed spherical aggregates that exhibited complete precipitation from the solution. Further studies on the properties of these systems are in progress and the results will be published elsewhere.

\section{Acknowledgements}

Financial support for this project from the IndoFrench Centre for the Promotion of Advanced Research, New Delhi (Grant no. 3605-2) is acknowledged. We thank the Institute Nanoscience Initiative (INI) at Indian Institute of Science, Bangalore, for providing TEM facility.

\section{References}

1. (a) 'Nanoparticle based inks and method of making the same' Nohr R S and Macdonald J G US Patent no. WO/2002/028660; (b) Magdassi S, Bassa A, Vinetsky Y and Kamyshny A 2003 Chem. Mater. 15 2208; (c) Santhanam V and Andres R P 2004 Nano Lett. 4 41; (d) Zheng Z, Yang M and Zhang B $2008 \mathrm{~J}$. Phys. Chem. C112 6597

2. (a) Yonezawa T, Onoue S-ya and Kimizuka N 2002 Chem. Lett. 31 1172; (b) Rowe M P, Steinecker W H and Zellers E T 2007 Anal. Chem. 791164
3. (a) Wohltjen H and Snow A W 1998 Anal. Chem. 70 2856; (b) Elghanian R, Storhoff J J, Mucic R C, Letsinger R L and Mirkin C A 1997 Science 277 1078; (c) Wie A, Kim B, Sadtler B and Tripp S L 2001 Chem. Phys. Chem. 2 743; (d) Rao C N R, Kulkarni G U, Govindaraj A, Sathishkumar B C and Thomas P J 2000 Pure Appl. Chem. 72 21; (e) Rao C N R, Kulkarni G U, Thomas P J and Edward P P 2000 Chem. Soc. Rev. 29 27; (f) Huang D, Liao F, Molesa S, Redinger D and Subramanian V $2003 \mathrm{~J}$. Electrochem. Soc. 150 G412; (g) Kuila B K, Garai A and Nandi A K 2007 Chem. Mater. 19 5443; (h) Bradbury C R, Zhao J and Fermin D J 2008 J. Phys. Chem. C112 10153

4. Xu, S, Hartvickson S and Zhao J S 2008 Langmuir 24 7492

5. (a) Mohr C, Hofmeister H, Radnik J and Claus $P$ 2003 J. Am. Chem. Soc. 125 1905; (b) Lou J, Lou Y, Maye M M, Zhong C J and Hepel M 2001 Electrochem. Commun. 3 172; (c) Jaramillo T F, Baeck S-H, Cuenya B R and McFarland E W $2003 \mathrm{~J}$. Am. Chem. Soc. 125 7148; (d) Pasquato L, Rancan F, Scrimin P, Mancin F and Frigeri C 2000 Chem. Commun. 2253; (e) Li H, Luk Y-Y and Mrksich M 1999 Langmuir 15 4957; (f) Mallikarjuna N N and Varma R S 2007 Cryst. Growth Des. 7 686; (g) El-Shall M S 2008 Acc. Chem. Res. 41783

6. (a) Bruchez Jr M, Moronne M, Gin P, Weiss S and Alivisatos A P 1998 Science 281 2013; (b) Cahn W C W and Nie S 1998 Science 281 2016; (c) Alivisatos P 2004 Nat. Biotechnol. 22 47; (d) Claridge S A, Goh S L, Frechet J M J, Williams S C, Micheel C M and Alivisatos A P 2005 Chem. Mater. 171628 ; (e) Nadagouda M N and Varma R S 2007 Biomacromolecules 82762

7. Cagno S, Janssens K and Mendera M 2008 Anal. Bioanal. Chem. 3911389

8. (a) Yonezzawa T, Yasui K and Kimizuka N 2001 Langmuir 17 271; (b) Hasobe T, Imahori H, Kamat P V, Ahn T K, Kim S K, Kim D, Fujimoto A, Hirakawa T and Fukuzumi S $2005 \mathrm{~J}$. Am. Chem. Soc. 127 1216; (c) Foos E E, Snow A W, Twig ME and Ancona M G 2002 Chem. Mater. 14 2401; (d) Son S U, Jang Y, Yoon Y K, Kang E and Hyeon T 2004 Nano Lett. 4 1147; (e) Gandubert V J and Lennox R B 2005 Langmuir 21 6532; (f) Yee C K, Ulman A, Ruiz J D, Parikh A, White $\mathrm{H}$ and Rafailovich M 2003 Langmuir 19 9450; (g) Ahonen P, Laaksonen T, Nykanen A, Ruokolainen J and Kontturi K $2006 \mathrm{~J}$. Phys. Chem. B110 12954; (h) Ray S, Das A K and Banerjee A 2006 Chem. Commun. 26 2816; (i) Vemula P K and John G Chem. Commun. 2006212218 ; (j) Wang X, Egan C E, Zhou M, Prince K, Mitchell D R G and Caruso R A 2007 Chem. Commun. 29 3060; (k) Sengupta A, Thai C, Sastry M, Matthaei J, Schwartz D, Davis E and Baneyx F 2008 Langmuir. 242000

9. (a) Daniel M-C and Astruc D 2004 Chem. Rev. 104 293; (b) van Bommel K J C, Friggeri A and Shinkai S 2003 Angew. Chem., Int. Ed. 42 980; (c) Love C S, Chechik V, Smith D K, Wilson K, Ashworth I and 
Brennan C 2005 Chem. Commun. 1971; (d) Ono Y, Nakashima K, Sano M, Kanekiyo Y, Inoue K, Hojo J and Shinkai S 1998 Commun. 1477; (e) Jung J H, Ono Y and Shinkai S 2000 Angew. Chem., Int. Ed. 39 1862; (f) Sugiyasu K, Tamura S, Takeuchi M, Berthier D, Huc I, Oda R and Shinkai S 2002 Chem. Commun. 1212; (g) Kobayashi S, Hanabusa K, Hamasaki N, Kimura M, Shirai H and Shinkai S 2000 Chem. Mater. 12 1523; (h) Kobayashi S, Hamasaki N, Suzuki M, Kimura M, Shirai H and Hanabusa K $2002 \mathrm{~J}$. Am. Chem. Soc. 124 6550; (i) Singh N and Lyon L A 2007 Chem. Mater. 19 719; (j) Vinod V P, Phadtare S, Joshi H M, Sastry M and Rao M 2007 J. Nanosci. Nanotechnol. 72767

10. Bhat S and Maitra U 2006 Chem. Mater. 184224

11. Kang S Y and Kim K 1998 Langmuir 14226

12. Brust $M$, Walker $M$, Bethell D, Schiffrin D J and Whyman R J 1994 J. Chem. Soc., Chem. Commun. 801
13. Calculated from $\mathrm{C} / \mathrm{H}$ analytical data of steroidcapped gold NPs

14. (a) Battacharya S and Srivastava A 2003 Langmuir 19 4439; (b) Bhattacharya S, Srivastava A and Pal A 2006 Angew. Chem. Int. Ed. 452934

15. The reaction time was limited to $12 \mathrm{~h}$ (max.). We have observed that more than $24 \mathrm{~h}$ of stirring in pyridine- $\mathrm{AcCl}$ led to decomposition of the system

16. (a) Shipway A N, Katz E and Willner I 2000 Chem. Phys. Chem. 1 18; (b) Soten I and Ozin G A 1999 Curr. Opin. Coll. Interf. Sci. 4 325; (c) Malikova N, Santos I P, Schierhorn M, Kotov N A and Marzan L ML 2002 Langmuir 18 3694; (d) Andersen P C and Rowlen K L 2002 Appl. Spectro. 56 124A

17. The 2-capped $\mathrm{Au}$ nanoparticles have similar dispersibility in $\mathrm{AcOH}$ while 3-capped $\mathrm{Au}$ nanoparticles were poorly dispersible in $\mathrm{AcOH}$ 